\title{
Some factors influencing nonmatching to sample in the monkey
}

\author{
R. C. ELLIOTT, E. NORRIS, and G. ETTLINGER \\ Institute of Psychiatry, London, England
}

and

\section{MISHKIN \\ National Institute of Mental Health, Bethesda, Maryland 20014}

Using the method of delayed nonmatching to sample with trial-unique objects, Mishkin and Delacour (1975) found high levels of object-recognition ability in experimentally naive monkeys: better than $75 \%$ correct performance in initial sessions, and learning to a $90 \%$ criterion in less than 100 trials and 25 errors. The present results suggest that this high level of performance was a function of the discriminability of the objects, the age of the animals, and perhaps also the quality of the reward.

In order to study cross-modal recognition by the method of nonmatching to sample with trial-unique objects (Norris \& Ettlinger, Note 1), an attempt was made to first replicate the observations of Mishkin and Delacour (1975) in vision. When the first group of animals did not perform as expected, two further groups were trained.

\section{METHOD}

Twelve monkeys were subjects. Group 1 consisted of two rhesus monkeys (Macaca mulatta) weighing 3.5 and $3.6 \mathrm{~kg}$, and two Cebus apella monkeys, each weighing $1.6 \mathrm{~kg}$. Group 2 consisted of four rhesus monkeys weighing between 2.5 and $2.7 \mathrm{~kg}$. And Group 3 consisted of four rhesus monkeys weighing between 2.1 and $2.6 \mathrm{~kg}$. Animals in Group 1 had extensive previous experimental training, but the other animals were untrained.

The methods of Mishkin and Delacour (1975) were followed exactly, except that a peanut rather than a grape was reward and the adaptation procedures were a little curtailed for Groups 1 and 2 . Also, Groups 1 and 2 were trained with objects from a special set of 400 used extensively in our laboratory for visual and tactile learning set (Jarvis \& Ettlinger, in press). Each of these objects was mounted on a cork that averaged $44 \mathrm{~mm}$ in diam and $15 \mathrm{~mm}$ in height; when the object was in place for testing, the top of the cork was flush with the top of the testing board. For Group 3 a new set of 100 objects was used. Like Mishkin and Delacour's, these objects were unmounted and included larger items than were contained in the first set.

The testing procedure for all groups involved presentation of a baited sample over the central well of a three-well board, followed $10 \mathrm{sec}$ later by re-presentation of this sample (now negative) together with a novel object (positive) over the lateral wells. Twenty such trials separated by $30-\mathrm{sec}$ intervals were given daily, each trial with a new pair of objects.

\section{RESULTS}

As shown in Figure 1, all three of our groups started at about $55 \%$ correct, some $20 \%$ less correct than the relevant group (Group E-NM) of Mishkin and Delacour.
Also, neither Group 1 nor Group 2 achieved 90\% correct performance, though Group 3 did so by the end of training. The difference in total error scores between Group 3 (median errors, 80) and each of our other two groups (median errors, 116 and 132, for Groups 2 and 1 , respectively) was significant at the .05 level (Mann-Whitney $U=1$ in each case). Group 3 did achieve a usefully rapid rate of learning. Nevertheless, Group 3 was still clearly inferior to Group E-NM.

\section{DISCUSSION}

Certain experimental factors not emphasized by Mishkin and Delacour (1975) apparently contributed to the high level of performance of their E-NM group.

First, the type of objects they used was important, as indicated here by the comparison between Group 3 and Groups 2

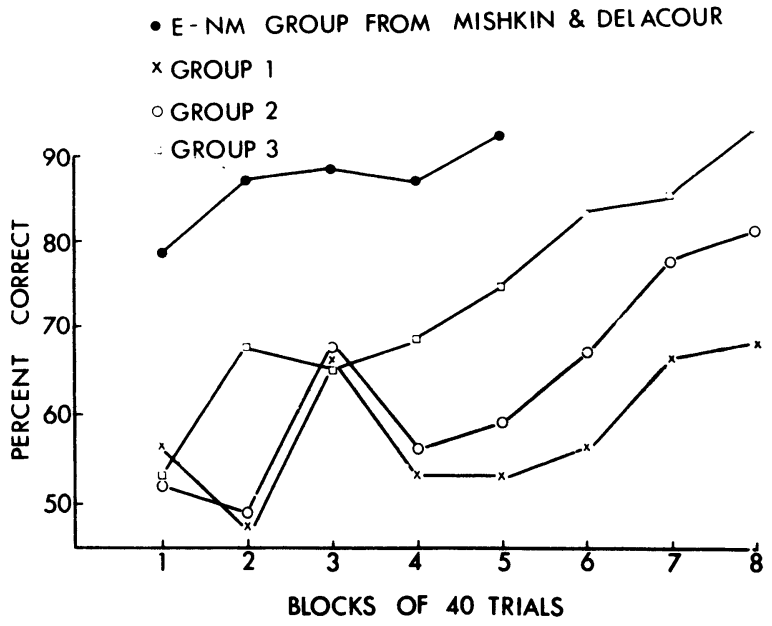

Figure 1. Comparison of the three groups from this experiment with Group E-NM from Mishkin and Delacour (1975). There was no consistent difference between the scores of the rhesus and Cebus monkeys of Group 1. 
and 1. Our procedure of mounting all objects on a uniform base may have reduced object discriminability, or it may have favored the use of many small items that were consequently less discriminable, or both. In any event, the use of free-standing objects of a wide range of sizes clearly improved performance.

Second, the animals' weight (i.e., age) was probably a factor. The monkeys in Group E-NM weighed from 3.5 to $5 \mathrm{~kg}$ and thus probably averaged 2.5 to 3 years of age (Gavan \& Hutchinson, 1973). By contrast, the monkeys in Group 3 weighed from 2.1 to $2.6 \mathrm{~kg}$ and so probably averaged about 1.5 to 2 years of age. Both groups were tested with the same type of objects, yet Group 3 was markedly inferior, perhaps because, being younger, they were more fearful of certain items or were simply less capable at learning and memory. Age-related improvements continuing even beyond 3 years have been reported in monkeys for similar problem-solving tasks (Zimmerman \& Torrey, 1965).

Finally, type of reward may have played a part, since this also differed between Group E-NM and Group 3. On the basis of an informal observation that monkeys prefer grapes to peanuts, grapes were used in the earlier experiment in a deliberate attempt to speed learning, and the attempt may have succeeded (cf. Harlow \& Meyers, 1952).

In short, the performance curve for Group E-NM can only be taken to represent the nonmatching performance of 2.5- to 3year-old animals trained with free-standing objects and preferredfruit rewards, all apparently highly favorable conditions.

\section{REFERENCE NOTE}

1. Norris, R. C., \& Ettlinger, G. Cross-modal nonmatching to sample in the monkey. In preparation.

\section{REFERENCES}

Gavan, J. A., \& Hutchinson, T. C. The problem of age estimation: A study using rhesus monkeys (Macaca mulatta). American Journal of Physical Anthropology, 1973, 38, 69-82.

Harlow, H. F., \& MeYer, D. R. Paired-comparison scales for monkey rewards. Journal of Comparative and Physiological Psychology, 1952, 45, 73-79.

JARvis, M. J., \& EtTlinger, G. Cross-modal recognition in chimpanzees and monkeys. Neuropsychologia, in press.

Mishkin, M., \& Delacour, J. An analysis of short-term visual memory in the monkey. Journal of Experimental Psychology: Animal Behavior Processes, 1975, 1, 326-334.

Zimmerman, R. R., \& ToRREY, C. C. Ontogeny of learning. In A. M. Schrier, H. F. Harlow, \& F. Stollnitz (Eds.), Behavior of nonhuman primates: Modern research trends (Vol. II). New York: Academic Press, 1965. Pp. 405-448.

(Received for publication December 30, 1976.) 